\title{
Curbing Consumer Financial Losses: The Economics of Regulatory Enforcement
}

Citation for published version (APA):

Faure, M. G., Ogus, A. I., \& Philipsen, N. J. (2009). Curbing Consumer Financial Losses: The Economics of Regulatory Enforcement. Law and Policy, 31(2), 161-191. https://doi.org/10.1111/j.1467-

9930.2009.00299.x

Document status and date:

Published: 01/01/2009

DOI:

10.1111/j.1467-9930.2009.00299.x

Document Version:

Publisher's PDF, also known as Version of record

Document license:

Taverne

Please check the document version of this publication:

- A submitted manuscript is the version of the article upon submission and before peer-review. There can be important differences between the submitted version and the official published version of record.

People interested in the research are advised to contact the author for the final version of the publication, or visit the DOI to the publisher's website.

- The final author version and the galley proof are versions of the publication after peer review.

- The final published version features the final layout of the paper including the volume, issue and page numbers.

Link to publication

\footnotetext{
General rights rights.

- You may freely distribute the URL identifying the publication in the public portal. please follow below link for the End User Agreement:

www.umlib.nl/taverne-license

Take down policy

If you believe that this document breaches copyright please contact us at:

repository@maastrichtuniversity.nl

providing details and we will investigate your claim.
}

Copyright and moral rights for the publications made accessible in the public portal are retained by the authors and/or other copyright owners and it is a condition of accessing publications that users recognise and abide by the legal requirements associated with these

- Users may download and print one copy of any publication from the public portal for the purpose of private study or research.

- You may not further distribute the material or use it for any profit-making activity or commercial gain

If the publication is distributed under the terms of Article $25 \mathrm{fa}$ of the Dutch Copyright Act, indicated by the "Taverne" license above, 


\title{
Curbing Consumer Financial Losses: The Economics of Regulatory Enforcement
}

\author{
MICHAEL FAURE, ANTHONY OGUS, and NIELS PHILIPSEN
}

\begin{abstract}
This article deals with the question of how a high level of compliance with consumer protection legislation designed to prevent financial losses can be secured. We use a theoretical framework based on economic analysis of law to address some of the key policy options, such as proactive and reactive monitoring, providing officials with postdetection enforcement discretion, administrative, civil, and criminal sanctions, and facilitating actions by victims and third parties. On the basis of our theoretical framework and a classification of jurisdictions into different groups (models of enforcement policy), we identify some key elements of an enforcement regime and indicate in what circumstances a particular solution can be expected to be more or less cost effective.
\end{abstract}

\section{INTRODUCTION}

There has been a sustained focus in the academic literature on the enforcement of regulation for more than thirty years (Hawkins 1984; Richardson et al. 1984; Grabosky and Braithwaite 1986; Vogel 1986; Ayres and Braithwaite 1992; Hutter 1997; Hawkins 2005; Yeung 2004; Baldwin and Black 2008). Indeed, in the 1970s and 1980s, particularly among socio-legal scholars, it came close to eclipsing interest in all other aspects of regulation. In retrospect it is not difficult to see why this occurred. There was a large disparity between the number of recorded regulatory contraventions and the number of formal condemnations, particularly criminal prosecutions, resulting from enforcement activity by the relevant regulatory agencies, and this clearly required some explanation. Regulatory scholarship, enhanced by empirical study, succeeded in repudiating intuitive assumptions that this was a case of pusillanimity by public officials or else the consequence of the excessive power of capitalist industrialists in a corporate state. Rather, it was asserted that compliance with regulatory obligations could, in general, be achieved without the heavy hand of formal sanctions by means of a combination of information, advice, persuasion, and (sometimes) threat.

Address correspondence to Michael Faure, Maastricht University School of Law, METRO, PO Box 616, 6200 MD Maastricht, the Netherlands. Telephone: +31-43-3883060; E-mail: michael.faure@facburfdr.unimaas.nl. 
That this so-called "compliance" approach to enforcement was and is able to achieve the regulatory goals more effectively than a "deterrence" approach, which implies a more regular and systematic use of formal legal sanctions, has nevertheless been assumed, rather than demonstrated and, within recent years, regulatory enforcement has become a matter of more serious policy debate. There has been a perception that, in the last decade or so, regulatory agencies have been persuaded by government to adopt a more punitive approach to enforcement (Simpson 2002; Baldwin 2004: 351). Whether or not this perception is justified, it is clear that regulatory enforcement recently has become an important matter of public policy debate as part of the campaign for "Better" (or sometimes "Smarter") Regulation (Ogus 2007: chap. 6). ${ }^{1}$

An important part of the debate has been to investigate how regulatory enforcement might be made more effective. In 2005 we were commissioned by the (then) UK Department of Trade and Industry to undertake a study of the effectiveness of enforcement regimes of consumer protection regulation. This was primarily a contribution to the program of examining best practice established by the Organization for Economic Cooperation and Development (OECD) Committee on Consumer Policy. We were invited to assess what enforcement regimes were likely to be the most effective in preventing contraventions of consumer protection regulations (resulting in financial losses only) in the light of theoretical work on the impact of enforcement measures and the practice of enforcement regimes in different jurisdictions. ${ }^{2}$

Our work took place at the same time as Professor Richard Macrory carried out, for the UK Cabinet Office, a wide-ranging review across many different regulatory enforcement regimes. He came to the conclusion that enforcement systems should involve less reliance on the criminal law and a greater use of administrative financial penalties (Macrory 2006), and, at the time of writing, there is a bill before Parliament to implement the proposals. ${ }^{3}$

In other jurisdictions, too, there have been significant developments in relation to enforcement policy, both before and after our work. ${ }^{4}$ Although the common aim of this reform activity is for more effective enforcement, the discussion has ranged over a variety of sanctions and procedures against a background of, within the industrialized world, very different legal and regulatory cultures. The task of our study was to determine what combination of sanctions and procedures, in different legal and regulatory cultures, were likely to be the most cost effective in achieving a high level of compliance with consumer protection legislation aimed at reducing financial losses.

To acquire information as to enforcement practices in different OECD jurisdictions, we sent questionnaires to members of the OECD Committee on Consumer Policy. On the basis of the responses to this exercise, we identified five models of enforcement (see Section II below). We then selected four case studies in order to study these different models of enforcement in more detail (one of the case studies covering two of the models), supplemented by information obtained via interviews with officials. 
For the theoretical perspective, we adopted an economic deterrence framework, derived from the basic model that Gary Becker formulated for the criminal law (Becker 1968: 169) and which has given rise to a very substantial literature (Eide 2000: 345-89; Polinsky and Shavell 2000: 38, 45). This is predicated on the assumption that individuals and firms will comply with the law if the costs incurred by them from contravening it (including notably any sanctions imposed) will exceed the benefits they derive from the contravention. As we shall see, the economic analysis focuses on how different approaches to key variables, such as the probability of a contravention being detected, the type of sanction imposed, and the procedural requirements for establishing liability for such sanctions, impact on the predictions of compliance derived from the model. And since those different approaches generate different levels of costs, particularly for the public purse, the analysis can make an important contribution to enforcement policymaking, in that it indicates how limited resources can be allocated so as to maximize the benefits to society arising from regulatory compliance - what is generally referred to as "cost effectiveness" analysis (Ogus 2006: 290-92).

Drawing on our OECD study, our aim in this article is to show how the economic framework can be used to make a meaningful contribution to the policy debate about appropriate enforcement systems. In Section II, we describe in more detail the five models and show how they address the key issues. Section III is devoted to the theoretical economic framework; and, in the remainder of the article, we draw from that framework implications for different dimensions of enforcement policy: the targeting of enforcement interventions (Section IV); self-regulation and alternative dispute resolution (Section V); procedures and processes (Section VI); and actions by victims and third parties (Section VII).

\section{MODELS OF ENFORCEMENT POLICY}

As stated above, for our OECD survey we obtained information from responses to questionnaires sent to representative officials in a large number of OECD jurisdictions. This related to enforcement law and practice in the following areas: monitoring of trader behavior, procedures following detection of contraventions, availability of sanctions (administrative, civil, or criminal) and procedures for these sanctions, and enforcement by consumers. On the basis of this information we were able to identify some key characteristics of enforcement. Moreover, because some patterns seemed to emerge, we were able to classify the responding jurisdictions into five groups, that is, five different models of enforcement policy. These models reflected the key characteristics of our investigations, notably whether a public agency engages in proactive monitoring of traders and whether financial penalties are imposed as a consequence of primarily administrative, civil, or criminal procedures (Faure, Ogus, and Philipsen 2008). ${ }^{5}$ The five models are: 
1. Jurisdictions in which there is a significant degree of monitoring and investigation by administrative agencies and, for the purposes of punishment and deterrence, there is reliance on the possibility of penalties being imposed as a result of criminal justice proceedings.

2. Jurisdictions in which there is a significant degree of monitoring and investigation by administrative agencies but efforts to secure compliance are focused on agencies taking proceedings against traders in the civil courts, although this does not preclude the possibility of criminal prosecutions.

3. Jurisdictions in which there is a significant degree of monitoring and investigation by administrative agencies and they themselves have the power to impose (generally modest) financial penalties. This does not preclude the possibility of criminal prosecutions or civil proceedings.

4. Jurisdictions in which a public institution (such as an Ombudsman) exists to receive complaints from consumers and third parties, and that agency may be instrumental in initiating proceedings in a civil court or referring the case for prosecution in the criminal courts.

5. Jurisdictions in which there is little or no monitoring of traders by an administrative agency, and it is mainly left to the consumers, aided by voluntary or publicly funded consumer associations, to enforce private rights against defaulting traders, or else to resort to self-regulatory dispute settlement processes. Administrative and/or criminal proceedings by a residual, public enforcement agency are taken only in exceptional cases.

To some extent these classifications reflect different legal traditions (as regards the judicial and administrative framework) and cultures (e.g., with respect to the role of the consumer), so that, for example, Anglophone/ common law jurisdictions tend to adopt mainly models (1) and (2), former members of the East-European bloc model (3), Scandinavian countries model (4), and Germanic countries model (5).

In our report for OECD, we undertook case studies in four jurisdictions, to explore in greater depth the key characteristics of the different models of enforcement policy. In the following paragraphs, only some key points that emerged from these case studies will be presented. In later sections of this article, we will take a closer look at several more specific aspects of these case studies.

The United Kingdom was selected as an example of model (1), that is, primarily relying on the criminal justice system for financial penalties. We found that enforcement procedures were considered in general to be effective. However, there was perceived to be inadequate deterrence for serious cases in the United Kingdom, because the penalties imposed by the criminal courts were too low, and no adverse financial consequences were attached to enforcement orders obtained in civil proceedings. The view of officials, that the introduction of a suitable system of administrative financial penalties would enhance compliance, anticipated the conclusions of the Macrory Report (Macrory 2006: chap. 3), and the government's legislative proposals. ${ }^{6}$ 
Australia was selected as an example of model (2) where administrative agencies use primarily the civil justice system to impose sanctions. We found that civil proceedings were (considered to be) an effective way of stopping illegal conduct by recalcitrant traders and achieving timely redress for consumers. In that respect also "probation orders" ${ }^{7}$ and adverse publicity were regarded as important devices for inducing compliance. The Australian civil regime does not allow the courts to impose financial penalties: although officials have been considering the possible introduction of civil pecuniary penalties for contraventions of consumer protection legislation, currently such penalties can only be pursued through criminal prosecution. In Australia, criminal sanctions are reserved for the most serious contraventions of the law. However, they were not generally considered an effective mechanism for achieving timely consumer redress because of the additional time and complexity associated with criminal prosecution.

Belgium was selected as an example of model (3) in which administrative agencies have power themselves to impose financial penalties. A first key point that emerged from our study is that the "transaction," that is, an administrative financial imposition, is considered to be an easy and low-cost means of dealing with consumer protection offenses. Furthermore, the ability of the criminal process to operate effectively in relation to cases appropriate for the process is perceived to be hampered by inadequate resources in the prosecution service and by the fact that some of the cases referred to that service could more appropriately be resolved in the civil courts.

The common feature of models (4) and (5), those primarily relying on consumer complaints to an ombudsman and those primarily relying on selfregulatory arrangements and the enforcement of private rights, is that they depend on a strong culture of consumer activism (see also Viitanen 2007: 81-103). ${ }^{8}$ For the fourth jurisdiction, reflecting this dominant characteristic of both models (4) and (5), we selected the Netherlands. The Dutch system works well where contraventions are easily detected and where traders are "benevolent." Industry self-regulatory compliance schemes can play an important complementary and cost-effective role to consumer policy enforcement regimes. Nevertheless, there was perceived to be inadequate deterrence for "mala fide" traders. It should be noted though that since 2007 a new administrative agency has been granted some powers to impose financial penalties (Ammerlaan and Janssen 2007: 105-21).

\section{THEORETICAL FRAMEWORK}

In this section we provide a short summary of the economic literature on regulatory enforcement, in order to be able to develop a theoretical framework that can be used to predict when traders are likely to comply with the law. Following Becker's study of the criminal law (1968), this economic literature is predicated on the assumption that individuals and firms comply with the 
law when the costs that they expect to incur if their unlawful act is detected and pursued will exceed the expected benefits that will accrue from the unlawful act. Naturally, the costs generated by the various enforcement policy options should be considered as well. The costs consist of (1) the administrative costs of using the particular enforcement advice and (2) the "error costs," that is, the adverse consequences to particular individuals and to society more generally if the processes generate some inappropriate condemnations and sanctions. With regard to error costs there is a well-known distinction between Type I errors, wrongfully convicting the innocent, and Type II errors, not convicting the guilty. Because the criminal justice system in particular is designed to reduce Type I errors (thereby increasing the probability of Type II errors), error costs are especially important when comparing administrative, civil, and criminal systems. In this section we also recapitulate on the cost-benefit approach (which identifies optimal levels of enforcement) and the cost-effectiveness approach (which takes a high level of enforcement as its goal). In our analysis below (Section IV and further), we will consider the benefits of enforcement of regulation.

\section{A. A SIMPLE MODEL OF DETERRENCE AND COMPLIANCE}

In Becker's (1968) model of deterrence, individuals and firms will be induced to comply with the law if their (expected) costs of contravening the law exceed the benefits to them of the contravention. The expected costs consist of the costs arising from the enforcement regime (D, the formal sanction), discounted by the probability of these costs being imposed (p). If the benefits - or utility - to traders of contravening the law are represented as $\mathbf{U},{ }^{9}$ the condition of compliance simply becomes $\mathbf{U}<\mathbf{p . D} .{ }^{10}$ However, it should be noted that the costs for traders arising from contraventions are broader than the sanctions imposed by the law. These costs include also, inter alia, legal defense expenditures, utility losses arising from encounters with aggrieved consumers and public officials, and market reputation losses. ${ }^{11}$ Some of these costs will be incurred regardless of whether there has been a formal conviction. Taking this into account, the condition of compliance can be rewritten as follows: $\mathbf{U}<\mathbf{q . E}+\mathbf{p . D}$. Here q.E represents the probability and the associated costs of the relevant act being detected, whereas p.D represents the expected costs of a formal condemnation. The variable $\mathbf{q}$ depends in particular on the amount and quality of monitoring of traders by enforcement agencies, the involvement of consumers, and the involvement of third parties such as consumer associations and competitors. The variable $\mathbf{p}$ is influenced by factors such as the requirements for formal hearings and proof of contravention (including burden of proof and powers to obtain required evidence), and proof of fault or knowledge.

This simple model of deterrence assumes that likely offenders behave rationally and have full information on the values of the different variables. The assumption of rational behavior can generally be regarded as plausible 
within the context of "white-collar crime," including contraventions of consumer protection regulation (Gibbons 1982) ${ }^{12}$ Indeed, it appears to make sense for policymakers to design enforcement systems having regard to the generality of behavior to be expected. The lack-of-information problem, however, may be more serious, in particular where it concerns information on the likelihood of detection and conviction ( $\mathbf{q}$ and $\mathbf{p})$ and on the formal sanction that will be imposed (D). Optimism, that is, a subjective valuation of $\mathbf{p}, \mathbf{q}$, and/or $\mathbf{D}$ below the actual value, results in undercompliance, whereas the opposite case would of course lead to overcompliance. Hence, providing information on the law and its sanctions may become an important strategy in order to reduce such problems of underdeterrence or overdeterrence. Polinsky and Shavell argue that, to predict how individuals behave, what is relevant is not the actual probability and magnitude of a sanction, but the perceived levels or distributions of these variables (2000: 325-26).

\section{B. COSTS AND BENEFITS OF ENFORCEMENT REGIMES}

In the literature, a distinction is generally made between a cost-benefit approach and a cost-effectiveness approach. In a cost-benefit approach, the optimal level of enforcement is identified by comparing costs and benefits. Naturally, quantifying benefits (reduction of social costs resulting from financial harm ${ }^{13}$ ) and costs (administrative and error costs) may prove to be rather difficult in practice (Ogus 2006: 283-87; Stigler 1970: 526-36). ${ }^{14}$ As far as benefits are concerned, it is necessary to ascertain the beneficial impact (B) in terms of achieving increased levels of compliance of the different enforcement policy options. As far as costs are concerned, the two categories of costs mentioned above are relevant. First, there are the administrative costs associated with the enforcement policy regime $\left(\mathbf{C}_{\mathrm{a}}\right)$, most of which fall ultimately on taxpayers. It is clear that some criminal penalties, such as imprisonment, are more expensive to apply than administrative or civil penalties. However, also the process costs are higher: the procedural requirements of criminal liability make it much more costly than administrative and civil procedures. Second, there are the error costs $\left(\mathbf{C}_{\mathrm{e}}\right)$ : costs arising from the fact that procedures and institutions are not perfect, and some decisions will erroneously impose sanctions or other losses on those who have not contravened the law. ${ }^{15}$ It is therefore important to secure some form of trade-off between administrative costs (notably process costs) and error costs.

A cost-effectiveness approach takes a high enforcement level as the goal. Then the important policy question is how this level of enforcement can be achieved at least cost. While the aim of our OECD project was indeed to assess the effectiveness of enforcement regimes in achieving a high degree of compliance with consumer protection regulation, here we also consider the question whether the benefits of regulatory enforcement are high or low.

From the information we acquired on the regimes in different jurisdictions, a number of policy options emerge, that is, alternative sanctions and institutional 
arrangements. These will be discussed in more detail in the following sections. Applying the simple theoretical framework to the different enforcement policy options makes it possible to hypothesize on how decisions on these options are likely to impact on $\mathbf{B}$ and $\mathbf{C}_{\mathbf{a}}+\mathbf{C}_{\mathbf{e}}$. To do this, the administrative and error costs incurred in exercising the option must be compared with the benefits, primarily in the form of increased compliance. Clearly, in order to answer the question whether, for a particular policy, option $\mathbf{B}$ is likely to outweigh $\mathbf{C}_{\mathrm{a}}+\mathbf{C}_{\mathrm{e}}$, empirical data on these variables are needed. Although for our study reliable data were not available (not even on administrative costs), it has been possible, as we will see in the following sections, to reach some intuitive predictions.

\section{TARGETING ENFORCEMENT INTERVENTIONS}

\section{A. MONITORING MODELS}

With regard to the monitoring of traders, jurisdictions vary in their approaches. For example in Australia, Belgium, and the United Kingdom publicly financed institutions adopt a proactive approach. In other jurisdictions, for example in the Netherlands, at least until recently, ${ }^{16}$ institutions rather adopt a reactive approach, relying largely on responding to the complaints of consumers and third parties.

What can be said concerning this choice between proactive or reactive monitoring from an economic perspective? The relevant question in terms of the model presented above is whether the administrative costs of an enforcement regime $\left(\boldsymbol{C}_{\boldsymbol{a}}\right)$ add significantly to $\boldsymbol{q} \cdot \boldsymbol{E}$ (probability and costs of being detected) and (to a lesser extent) of $\boldsymbol{p} . \boldsymbol{D}$ (probability and costs of a formal sanction being imposed). Generalizations seem difficult because the relative merits of the two approaches are likely to depend much on circumstances arising in particular jurisdictions, including their institutional arrangements and their consumer protection culture. Nevertheless, it seems possible to identify a few indicators to predict when the one or the other approach may be more effective in curbing contraventions of consumer protection legislation.

A first indicator is whether, in the particular jurisdiction, an active consumer culture exists and whether there is an already existing agency network. The relevance of the latter is that a proactive approach requires significant resources to be available to public agencies. However, the marginal costs of those resources are likely to be smaller, and therefore the argument for the proactive approach more powerful, if an agency network already exists for other purposes. To similar effect, the reactive approach is plausible in countries (such as the Netherlands) where there is a culture of consumer activism. This is likely to be the case where consumer associations and the like, whether voluntarily or publicly funded, have a major profile in the 
sense both that consumers will be sufficiently aware of their existence in order to refer cases to them, and that the institutions themselves take the initiative in publicizing potential problems and seeking out defaulting traders (Micklitz 2007: 11-33; Van Boom and Loos 2007: 229-54). ${ }^{17}$ However, this assumes that the consumer institutions are effectively able and likely to take action against defaulting traders, which may not always be the case, particularly if enforcement powers are misused for opportunistic reasons (Schäfer 2000: 183-213; Van den Bergh 2007).

A second indicator relates to the nature of the consumer protection measure in question. In relation to those that most consumers will themselves be unlikely to detect, proactive monitoring should add significantly to $\boldsymbol{p}$ and $\boldsymbol{q}$, and thereby also to deterrence. Examples include unsound investment advice by a financial consultant, nontransparent price calculations (Van den Bergh 2007: 186) and "signing-without-reading" standard form contracts (De Geest 2002: 213-325). These can be contrasted with contraventions on which consumers are likely to be much better informed, for example, those giving rise to a disappointing holiday (Van den Bergh 2007: 195). The information characteristics of the latter cases provide, indeed, an indicator not only for reactive monitoring, but also for the possibility the private enforcement might, more generally, be preferable, a dimension that we consider in Section VII of this article.

A third indicator is the information available to firms concerning the contents of the rules. If firms are badly informed about the contents of the rules, ex post enforcement will impose costs on them that could have been prevented in an ex ante monitoring regime. In such circumstances, proactive monitoring can serve to educate a proportion of the relevant traders as to what is needed to comply with the law, and this can also enhance further compliance.

The latter argument derives some support from studies of enforcement styles. It appears that many violations of regulation are not intentional, but rather result from lack of information or knowledge. In such cases a proactive approach has the advantage that, through education and information provision, firms (who may not even have been aware that they were violating) can be led toward compliance (Fenn and Veljanovski 1988: 1055-70). Thus, a system of proactive monitoring of traders by public authorities is likely to be cost effective when there is not a significant culture of proactive complaints by consumers and consumer associations within the jurisdiction, where the contravention is unlikely to be easily detected by the consumers themselves, and where information costs for traders are high.

It equally follows that there is likely to be a significant enforcement deficit and thus underdeterrence in those jurisdictions adopting a reactive approach in relation to consumer protection contraventions that are not easily detectable (Van den Bergh 2007: 191). This was a serious weakness in the Netherlands before the introduction of the consumer authority. Even difficult to detect contraventions like nontransparent (or wrong) price calculations were not 
subjected to proactive monitoring by public agencies. ${ }^{18}$ In such jurisdictions, the question also arises as to how well the complaints and dispute-resolution procedures perform in inducing compliance. However, even if the systems are effective, the weakness remains that they only react after the harm occurs and therefore many infringements may remain undetected (ibid.: 191-93). ${ }^{19}$

The cost effectiveness of proactive monitoring can moreover be enhanced by the adoption of risk-assessment models such as those used in the United Kingdom (Howells 2007: 63-80). Targeted enforcement has the advantage that it generates a higher rate of detection $(\boldsymbol{q})$ for each unit of input but can be adopted as a policy without the use of a formal model of risk assessment. ${ }^{20}$ Nevertheless, it is important that any such targeting be based on objective rather than subjective criteria, since the latter may too easily permit the intrusion of political and other undesirable considerations into the appraisal. The objective criteria would include, for example, the number of complaints relating to particular categories of trader as well as cases where, because of information asymmetries, the risk of underdeterrence is higher (Van den Bergh 2007: 198).

\section{B. POST-DETECTION DISCRETION}

When an agency believes that a contravention has taken place, it typically has a wide range of enforcement options, from taking no action other than an informal warning, to issuing a formal warning, to initiating administrative, civil, or criminal procedures. It appears that the only plausible argument for denying enforcement agencies the discretion as to whether or not to initiate an enforcement action, and in what form, is derived from concerns with problems concerning the transparency and accountability of officials, in short where discretion can be abused.

The question of discretion is strongly linked to a debate in the enforcement literature between advocates of the deterrence model (who would limit agency discretion) and advocates of a cooperative enforcement style (which relies on negotiations between the agency and the regulated and for which, therefore, discretion is important). Although it is of course not difficult to point to the risk of capture arising from a cooperative strategy (May and Winter 1999: 625-51), ${ }^{21}$ a pure deterrence approach, which would eliminate all agency discretion cannot be cost effective (Hawkins 1984). A cooperative strategy can be qualified as a "soft" approach that may endanger the goal of optimal deterrence (see also Van den Bergh 2007: 197), but the main reason for allowing agency discretion is related to the high costs to the enforcing agency in bringing a case to court (Ogus and Abbot 2002: 293). Of course, the agency's discretion can also have disadvantages. Discretion may be very costly to the agency (e.g., if discretion leads to a larger number of appeals).

There are two strong cost-effectiveness arguments for discretion. First, although the automatic pursuit of enforcement measures obviously raises 
the value of $\boldsymbol{p}$, and therefore, under the deterrence model, should increase compliance, the social benefit of such increased compliance in relation to trivial contraventions is relatively small. Proceeding with trivial cases in this way may add disproportionately to the costs $\left(\boldsymbol{C}_{\boldsymbol{a}}\right)$, because traders will sustain significant "indignation costs" that may motivate them to initiate appeals against decisions (Bardach and Kagan 1982). Second, dismissing the casewith or without a warning - might not, in relation to first-time offenders, directly increase compliance, but it should generate significant benefits in terms of educating these traders, and this should indirectly improve future compliance. Thus, the agency can improve the knowledge of market participants by giving opinions on the legality of certain practices (see also Van den Bergh 2007: 201). Furthermore, if the exercise of these options is followed by increased monitoring of the traders concerned, it should lead to a major impact in deterring second-time offenders, because, for these offenders, the chance of getting caught $(\boldsymbol{q})$ will have a much higher value (Fenn and Veljanovski 1988: 1055).

The cost effectiveness of these options depends crucially on the relative importance of inducing compliance by first-time and second-time offenders, respectively. If, as is typically the case with consumer protection regulation dealing exclusively with financial losses, relatively small amounts of harm result from individual contraventions, and the problem is mainly with those traders who are regular offenders, then the discretion not to engage in an enforcement regime, if wisely exercised, is of great importance. A trader responsible for a single, and perhaps accidental, contravention will lose little, and may gain, through being better informed; the repeat offender is more likely to be caught and the subject of a formal condemnation.

It may therefore be concluded, that, unless there are justified fears that officials might abuse discretion, it is cost effective for agencies to have the power to choose between dismissing a case (with or without a warning) and initiating enforcement procedures. This accords with the more general insight from the law and economics literature (ibid.) and from the environmental area (Heyes and Rickman 1999: 361-78) that, given limited agency resources for inspections, it is cost effective for enforcement agencies to use tolerance in some contexts (first offenders) and increasing coercion in others (second offenders).

\section{SELF-REGULATION AND ALTERNATIVE DISPUTE RESOLUTION}

As we have seen, model (5) adopts a strategy that, because of its heavy reliance on the activism of consumers themselves and/or associations representing their interests, as well as the readiness of traders to reach solutions through self-regulatory mechanisms, involves a much reduced role for public institutions. This leads to a first observation, that if such a system is able to achieve compliance, it will typically do so at a significantly lower administrative 
cost than if public enforcement processes are invoked. A second, related point is that, since consumers and consumer associations have an interest in the outcome of the case, they are motivated to pursue it in an efficient way; officials of public enfofircement agencies do not have the same motivation, because they do not need to balance the benefits of enforcement against the costs (Landes and Posner 1975: 1). Of course, as we have seen in Section IV, the benefit of such motivation may be outweighed by the costs to the private parties of having information concerning the contravention, and of taking the initiative in pursuing a claim against the trader. This advantage to private enforcement is therefore likely to apply only in jurisdictions with a culture of proactive consumerism.

The absence of a formal public process and sanction also means that the costs to be incurred by the trader following contravention, particularly those associated with $\boldsymbol{D}$, are less explicit. It is important, therefore, to consider under what conditions these self-regulatory procedures can generate adequate deterrence (Hadfield 2001: 40). The first is obvious but needs to be stated. Systems of self-voluntary regulation will emerge in particular industries only when it is in the interest of members of that industry to have them (Gupta and Lad 1983: 416). This might be because the system increases overall demand for the industry's product by, for example, raising consumer confidence that deviant behavior by individual traders can be better controlled; or because the costs to the industry arising from the system are less than those incurred under a conventional publicly enforced system. For the latter condition to be satisfied, the coordination costs within the industry must be relatively low, thus implying a professional (or trader) association with strong and effective powers over its members (and the ability to control free-riders) (Wotruba 1997: 41) or at least the use of "trustmarks," which are used by consumers as a signal of reliability and which can be withdrawn by the association in cases of default (Calliess 2008). Care must also be taken that the self-regulatory arrangements do not fall foul of competition law.

Of course the powers exercised by the self-regulatory organizations (SROs) over their members must include the ability to impose sanctions and, so that the cost advantages of the system can be maintained, without proceedings in the ordinary courts. Now, just as with public enforcement systems (Ayres and Braithwaite 1992), SROs can, and indeed do, use a pyramid of instruments, enabling them to respond with measures and sanctions of increasing severity if traders continue to default on their obligations (Scott 2004: 453, 498). As well as advice and warnings, the sanctions can include financial penalties and the suspension or expulsion from membership of the association. In certain contexts, indeed, when such membership is vital for the trader's market reputation, these latter sanctions can generate high values for $\boldsymbol{D}$.

Nevertheless, the existence of instruments capable of generating adequate deterrence does not of course necessarily imply that they will be used to 
that end. The degree of commitment of an SRO to securing compliance will vary according to the nature of the trade and its particular characteristics, but some generalizations can be made (Hadfield 2001: 43-44). The SRO will benefit from securing compliance from its members if an increase in the demand of consumers for the products and services supplied by the organization's traders and bearing the trustmark justifies the costs of the measures taken to secure compliance. ${ }^{22}$ The key variable affecting that demand is reputation, not only that of the traders themselves, but also that of the SRO's ability adequately to police its members' compliance with their regulatory obligations. For that purpose, the enforcement mechanisms must be seen to be effective, with some degree of transparency of the processes, using, for example, modern technological means, such as the Internet.

In many areas of trade, the costs of coordination and of information adequate to reassure consumers will be too high, relative to the benefits that will accrue; and the deterrence model will fail. There are, however, institutional arrangements that can solve the problem while still retaining the principal features of self-regulation. As one of us has argued elsewhere (Ogus 1995: 97), it might be possible to establish competition between two or more trustmarks within a particular trade. Such competition will enhance the importance of maintaining the reputation of the trustmark and will thus exert pressure on the SROs to secure adequate compliance with regulatory obligations by its members. The alternative is to impose some form of public accountability on the SRO. This can be done by a public agency supervising the activities of SROs, but there are many other arrangements with some coordination of public institutions and self-regulatory structures, generally referred to as systems of co-regulation (Bartle and Vass 2007: 885).

\section{SANCTIONS AND PROCESSES: ADMINISTRATIVE V. CIVIL V. CRIMINAL}

After a violation has been detected, and the agency decides that some form of public enforcement is necessary, the question arises which sanction (and concomitant process) should be invoked. The main possibilities are administrative sanctions, civil law sanctions, and criminal sanctions, and we will compare the relative cost effectiveness of each. Here we consider civil law only as an instrument used by the agency against the trader; the possibility of victims using their private rights will be addressed in Section VII.

\section{A. ADMINISTRATIVE SANCTIONS}

Although, in common law jurisdictions, traditionally the public enforcement of regulation has relied predominantly on criminal law, in other countries, administrative agencies have had wider powers to impose financial penalties, ${ }^{23}$ and, as we have already seen, there appears to be an increasing tendency to adopt the device for some aspects of consumer protection. The appropriateness 
of the sanction, the form it should take, and the process by which it should be imposed nevertheless remain important questions for debate (Macrory 2006: chap. 3).

The analytical framework based on deterrence theory would tend to support conferring such power on agencies. For the condition of compliance $(\boldsymbol{U}<\boldsymbol{q} \boldsymbol{E}+\boldsymbol{p} \boldsymbol{D})$ to be met in typical cases the variable $\boldsymbol{p D}$ (the formal sanction discounted by the probability of it being imposed) must be reasonably high if it is to exceed the profit accruing from the contravention $(\boldsymbol{U})$, because $\boldsymbol{q} \boldsymbol{E}$ (the costs to the trader of being detected discounted by the probability of this occurrence) is generally rather low. If financial penalties are only available in the criminal or civil judicial processes, then given the significant administrative costs of these processes (particularly the criminal processes if there is a high threshold of evidence necessary to secure a conviction there), the probability of the penalty being imposed $(\boldsymbol{p})$ will be relatively low (Garoupa and Gomez-Pomar 2004: 410; Van den Bergh 2007: 198). ${ }^{24}$ To compensate for the low $(\boldsymbol{p})$, the courts might impose a relatively large penalty. But, although courts generally have the power to do this, in practice, they are very reluctant to do so for minor trading offenses. In consequence, in such systems, there is likely to be a problem of insufficient deterrence.

One means of addressing these issues may be the use of administrative financial penalties. If, as is assumed here, these are readily imposed in cases (notably involving second and repeat offenders) where deterrence is considered to be important, then, in such cases, $\boldsymbol{p}$ will be high thus requiring only a relatively modest penalty $(\boldsymbol{D})$ for the compliance condition to be met. Moreover, this is done with a considerable saving in administrative costs $\left(\boldsymbol{C}_{a}\right)$.

By way of qualification to this, it must be recognized that administrative financial penalties are likely to give rise to higher error costs $\left(\boldsymbol{C}_{e}\right)$, because without the higher evidentiary thresholds required for liability in the criminal and civil justice systems, some administrative penalties will be wrongly imposed - what we have already referred to as Type I errors. The consequences of such errors can indeed be serious. ${ }^{25}$ They include not only the financial and other costs inappropriately imposed on a trader, but also the wider costs that result from overdeterrence, since the latter can have a chilling effect on innovation and competition (Van den Bergh 2007: 199). Therefore, in determining the appropriateness of a system of administrative penalties, there is a need to weigh these costs against Type II error costs, those arising from underdeterrence.

In relation to the design and operation of a system of administrative financial penalties, the first question, that of terminology, might be considered to be relatively trivial, but it is not unimportant. Given issues of accountability, the stigma associated with certain forms of condemnation, and therefore also error costs, it appears preferable that the language typically associated with the criminal process (for example, "fine" or "penalty") should be avoided. Hence, perhaps, language such as a "financial notice" or "charge" is preferable. 
A second question is whether the financial penalty should be fixed or variable, at the discretion of the agency (though to a specified limit). From a deterrence perspective, there are clear advantages to the latter since the amount imposed can be made to reflect relevant economic criteria, such as the probability of detection and punishment and the amount of the social loss caused, as well as the trader's wealth and the profit likely to be derived from the contravention $(\boldsymbol{U})$ (Becker 1968; Polinsky and Shavell 2000; Kobayashi 2001: 715) ${ }^{26}$ So also the uncertainty generated by a discretionary approach might add to the costs for the offender and thus aid deterrence. On the other hand, fixed penalties can be processed at lower administrative cost. In addition, the exercise of discretion regarding the amount might encourage more appeals and/or create problems of divergence of approach between different offices. On balance, it would seem that it is cost effective for fixed penalties to be used only for very minor offences. For others, the agency should have discretion, up to a limit, and to maintain some uniformity of approach, decisions regarding the amount should be made at a central, rather than a local, level.

As regards the procedure governing the financial penalty, there would appear to be two main models (Macrory 2006).

i. As in Belgium, a formal allegation of commission of a criminal offense is made. The trader is nevertheless given (by the administrative agency) the option of accepting a "proposal" for payment of a specified sum. If the proposal is not accepted, or payment is not made within a prescribed period, the trader will normally be prosecuted in a criminal court. Conversely, on payment, the criminal charge lapses. (Note that this model could be used in relation to civil, rather than criminal, proceedings.)

ii. As in the Netherlands and the United Kingdom, if current legislative proposals are implemented, the imposition of the administrative financial penalty is independent of any criminal (or civil) process, but the trader has the right to bring an appeal against the imposition to a tribunal or court.

The choice between the two models may depend on the related phenomena of administrative costs $\left(\boldsymbol{C}_{\boldsymbol{a}}\right)$ and error costs $\left(\boldsymbol{C}_{e}\right)$, and the incidence of these costs may vary from jurisdiction to jurisdiction, according to differences in legal culture. Take first, model (i). Of course, if traders consider the decision to be wrong, they can refuse the proposal, thus relying on adjudication in the criminal (or civil) court. But there are other, cheaper ways of constraining errors. For example, the administration can be required to provide a significant amount of detail in the allegation, and the trader may be given the possibility of disputing the content of the allegation before the formal imposition is made. Then, as regards model (ii), in addition to the right of appeal, the trader may be given the opportunity to respond (in writing) to a formal allegation or to attend an oral hearing in which the allegation is contested. Allowing the regulator to impose administrative penalties on a business 
tends to shift the burden of proof onto the business to prove its innocence. Adequate evidentiary standards and procedures at the administrative stage may, however, reduce this risk, as well as avoiding the increased costs associated with an appeal. ${ }^{27}$

Clearly, the more elaborate the procedures, the higher the administrative costs but also the lower the error costs. It is not easy to generalize on the optimal trade-off between these two sets of costs, particularly because the different styles of legal procedures generate different levels of costs in different jurisdictions. However, the following predictions are proffered. In jurisdictions, such as those in the common law world, associated with more complex criminal law procedures and higher evidentiary thresholds for criminal liability, model (ii), with a right of appeal to an administrative tribunal, is likely to be less costly. Conversely, in jurisdictions where these conditions do not apply, model (i) is likely to be more cost effective.

Other sanctions are often available to administrative agencies, including the power to order that victims be compensated and the reimbursement of (some of) the administrative costs of enforcement. In many jurisdictions an administrative authority can issue a "cease offense" order, a prohibition order, or an injunction. All of these have as goal to seek future compliance. Especially in cases where excessive penalties may result in overdeterrence a cease and desist order, which simply aims at the discontinuation of the infringement, may be the preferred sanction (Van den Bergh 2007: 199-200).

In some cases administrative authorities may also have the power to order the compensation of the victim or the reimbursement of (some of) the administrative costs of enforcement. The amounts involved may, for deterrence purposes, usefully complement financial penalties, should these be set at too low a level. The appropriateness of adverse publicity ("naming and shaming") is debated in the literature. It is clear that the device can achieve additional deterrence at relatively low cost (Morris and Tonry 1990; Buell 2006: 473 537). On the other hand, offenders respond to the device in different ways and targeting the sanction on those for whom the impact will be greatest is not easy (Posner and Rasmusen 1999: 369-82; 2003: 2186-207). In any event, it would seem to be inappropriate in the context of an administrative decision, unless the latter is followed by a definitive ruling by a court (for example, following an appeal). The reason is that error costs can escalate if the agency has reached an incorrect decision, and reversing it on appeal will not significantly reduce the harm arising from adverse publicity.

\section{B. CIVIL SANCTIONS}

The first issue is whether a civil court should have power to impose financial penalties on traders guilty of contravening consumer protection regulation and when in practice it should be exercised. There appears to be no strong argument for denying this power to the civil court, although it may not always be compatible with particular legal cultures. The question of when it 
should be exercised is more delicate and assumes particular importance if, in a given jurisdiction, for one policy reason or another, administrative agencies are not allowed themselves to impose financial penalties. It is assumed here that financial and other penalties will, in any event, be available in criminal proceedings. What are the relative advantages and disadvantages of civil and criminal financial penalties respectively?

In many jurisdictions, there will be significant differences in the evidentiary threshold required as between civil and criminal liability. It may also be the case that some degree of knowledge, intention, or blameworthiness must be proved in the criminal context, while these conditions are not so stringent in the civil justice context. These differences normally make the preparation and adjudication of the criminal prosecution significantly more expensive than the civil claim. For most cases, that should make the civil process more cost effective than the criminal process. On the other hand, the increased cost of criminal proceedings must be weighed against the possibility that the imposition of the penalty there will have a greater deterrent effect. That may be both because a criminal conviction carries a "stigma," which may exist to a lesser degree in civil condemnations (Van den Bergh 2007: 198), and because the criminal court may have additional sanctions to secure compliance, which are not available in civil proceedings (for example imprisonment).

For jurisdictions where the cost of the criminal process significantly exceeds that of the civil process, we can therefore reach the following conclusion. If the administrative processes (which may or may not include a financial penalty) fail to deter contraventions, the imposition of a civil financial penalty may be a more cost effective means of enhancing compliance than a criminal financial penalty, except where increased deterrence resulting from the criminal process justifies the increased cost.

In many jurisdictions, civil proceedings are taken against a trader formally to prohibit any continuing or further contraventions by means of an injunction, an enforcement order or a cease offense order. In terms of deterrence, it is not clear that this device is likely to be significantly more effective than when an equivalent order is issued by an administrative agency, except to the extent that the court setting has a psychological impact on the trader's propensity to comply or that the court injunction or order carries additional penalties not initially available. The greater publicity attached to court orders may also serve to deter other traders. But, because obtaining a civil justice order is much more costly than issuing an administrative order, additional arguments must be invoked to justify it.

One such argument may arise from a concern to prevent continuing unlawful activity in the individual case rather than to deter more generally. The power of the court to uphold the order by means of further sanctions, such as imprisonment for contempt (common law jurisdictions), or accumulating financial penalties (civil law jurisdictions) is available for this purpose. The order may thus be effective to prevent serious amounts of harm that may 
arise from continuing or further contraventions. Even a harsh criminal justice regime may "bite" too late to avoid these consequences. It is therefore concluded that a civil injunction or enforcement order is justified where continuing or further contraventions will lead to such a level of social harm that prevention of the continuing unlawful activity is regarded, in the individual case, as essential.

If, within the relevant jurisdiction, there is a system of trade licensing operating in relation to the activity that gives rise to the contravention, then it may be possible for a court to suspend or revoke the licence. This is a severe penalty, as potentially it deprives traders of their chosen livelihood, and, for deterrence purposes, it is likely to be much more effective as an ultimate penalty than imprisonment, which, as we shall see, is the most severe criminal law penalty. Although postimposition monitoring is necessary to ensure that the trader does not continue the trading activity, it is certainly a less costly option than imprisonment. Moreover, to traders it may appear to be a more realistic possibility than imprisonment since the reluctance of courts to imprison traders for relatively minor offenses is well known. Of course, like imprisonment, a wrong decision can give rise to very large error costs $\left(\mathbf{C}_{\mathrm{e}}\right)$; therefore a court decision justifying the suspension or revocation is essential.

In the absence of a licensing system, the equivalent outcome can be secured by what is sometimes called "negative licensing" (Ogus 2004: 222), a judicial order depriving the defendant of the right lawfully to practice a specific trade or profession. Although such a "cease trading" order potentially may be as powerful a sanction as the suspension or revocation of an actual licence, there may be problems in defining the scope of the prohibition for it to be legally effective. It is thus concluded that, as an ultimate sanction, the suspension or revocation of a trading licence is likely to be much more cost effective than imprisonment. The same may apply to a cease trading order where the scope of the order can be defined with sufficient precision. Finally, it is noted that the imposition of a criminal sanction may have similar consequences for individuals, as in a number of jurisdictions there will be associated restrictions on, for example, the ability to undertake international travel, or to be a director of a publicly listed company.

\section{CRIMINAL SANCTIONS}

In most legal systems, there is recognition that criminal law should continue to play a role in relation to the enforcement of consumer protection legislation and, moreover, that it is important, for general deterrence purposes, for the criminal process to be seen to be used on occasions. Putting the same point another way, if traders generally perceive the value of $\boldsymbol{p}$ (the probability of a conviction) to be significantly higher than in reality is the case, there is no reason to disturb this impression, if it can contribute to a higher level of compliance (Hawkins 2005) ${ }^{28}$ Subject to that consideration, it is possible to 
identify some characteristics of a case that are likely to render a criminal prosecution cost effective.

The criminal justice system is necessary to induce compliance where alternative systems provide, or are likely to provide, inadequate deterrence. A simple, if also crude, indicator of inadequate deterrence is the existence of a second or subsequent contravention. A plausible enforcement policy might then be to engage in the high cost of a criminal prosecution only if a trader is known already to have committed the same or an equivalent contravention. Such a policy might involve a presumption that, in the large majority of cases, $\boldsymbol{q} \boldsymbol{E}+\boldsymbol{p} \boldsymbol{D}$ from noncriminal processes would exceed $\boldsymbol{U}$ and thus be adequate to induce compliance. In some individual cases, a second or subsequent contravention might reveal that the presumption was not justified, perhaps because of the size of $\boldsymbol{U}$, perhaps because the trader was insufficiently aware of the law and its consequences. The use of the criminal justice system thus can involve a switch from general deterrence to individual deterrence.

In accordance with the analysis above, this argument presupposes that the costs to society arising from first-time contraventions are not so high as to render deterrence of them a priority. It may be the case that some consumer protection measures do not fall into this category: if so, there is a strong argument for invoking the criminal justice process at an earlier stage. This corresponds with general economic criteria for the use of the criminal law. They predict that criminal law (rather than civil or administrative) may be needed where the probability of detection is very low, and the gain to the offender very high. In combination with a potential insolvency risk, this means that either very high financial penalties should be applied or (in case of a risk of insolvency) nonmonetary penalties. In both cases, the reduction of error costs requires the application of the criminal law with its higher evidentiary threshold (Bowles, Faure, and Garoupa 2008).

The character of the criminal justice system is assumed to be concerned not only with deterring and repressing unlawful conduct, but also with reflecting moral values within a given society regarding what is "wrongful." As such, as already noted, the evidentiary threshold and other conditions for criminal liability (including possibly requirements of blameworthiness) tend to be more exacting than those in other processes. They also typically generate significantly higher administrative costs. The justification for the special features of the criminal process is clear: the penalties that a criminal court can impose, including imprisonment, can be most severe, and, in addition, a stigma often attaches to those with criminal convictions (Rasmusen 1996: 519; Funk 2004: 715). Both of these phenomena add substantially to error costs in the event of wrongful convictions, and the special features alluded to reduce the risk of such errors being made.

The principal enforcement function of the criminal justice system in relation to consumer protection legislation can thus be considered to deploy an ultimate set of sanctions appropriate for those traders who have not 
been, or will not be, deterred by other instruments (perhaps conveniently to be referred to as "rogue traders"). Other factors that will be relevant in determining whether criminal sanctions should be pursued include, for example, the level of individual consumer detriment associated with the conduct, whether the conduct and/or resultant detriment was widespread, whether the conduct was deliberate or particularly negligent, and the level of cooperation by the defendant with the investigation.

It is not easy to define exactly the characteristics of a rogue trader. They should certainly include repeat offenders who cannot be deterred by other means. But this should not exclude other characteristics that would reflect the moral values of the criminal law. It might therefore be inappropriate to attempt a more specific definition, other than that the conduct is regarded as so repugnant as to justify a criminal prosecution even where this is not justified by reference to deterrence arguments. And, of course, what satisfies fiat test is likely to vary across countries, because, in different jurisdictions, different views will be held on what kinds of conduct should be the subject of criminal processes.

The above perspective of the function of the criminal law in relation to the enforcement of consumer protection legislation has important implications for the procedures and substance of the criminal justice process. If the requirements of a prosecution authority, a high evidentiary threshold for liability, and conditions of knowledge and blameworthiness are considered necessary to reflect the moral values implicit in criminal justice, then these should be preserved for consumer protection legislation even though, for reasons given above, they may not always be consistent with cost-effective deterrence.

What, then, of the sanctions that can be imposed by the criminal courts? Fines are the criminal law equivalents to administrative financial penalties and are frequently used for reasons that we explored in the administrative sanction context. The principal advantage of the instrument is that the amount can be determined by reference to the deterrence goal, so that when discounted by the probability of the sanction being imposed $(\boldsymbol{p})$ and when added to $\boldsymbol{q} \boldsymbol{E}$, it exceeds the trader's profits $(\boldsymbol{U})$ and is thus likely to induce compliance, and at relatively low administrative cost.

The use of imprisonment may in extreme cases be rationalized by reference to the moral outrage generated by the trader's conduct or by the need to protect the public against further wrongdoing generating large amounts of damage. It is very difficult to justify its use as a cost-effective deterrent because of the huge cost it imposes both on the taxpayer and on the convicted traders themselves. Although imprisonment is sometimes resorted to when defendants do not have the means or the willingness to pay a financial penalty, there are other sanctions that are likely to be more cost effective in ensuring compliance.

Disgorgement of profits obtained by means of, or confiscation of, goods connected in some way with the contravention may be impracticable in relation to most consumer protection contraventions. But, where it is feasible, it may help to solve the problem identified in the last paragraph, when a 
trader has insufficient wealth or available assets for an appropriate financial penalty to be effective (Bowles, Faure, and Garoupa 2000: 537-49; 2005: 275-95).

\section{ACTIONS BY VICTIMS AND THIRD PARTIES}

In some jurisdictions, the consumer victims and third parties are able themselves to initiate, or participate in, administrative enforcement proceedings or criminal prosecutions. Quite apart from this, since many contraventions of consumer protection regulation constitute also infringements of the consumer victims' private rights, especially those arising under contract law, private law actions may also be available. ${ }^{29}$ The question thus arises as to the extent to which actions by victims and third parties may contribute to efficient enforcement policies.

Take first private rights. When these are enforced, or traders perceive that such enforcement is plausible, this will enhance the inducement to compliance supplied by the public system, in that it will add significantly to $\mathbf{q E}+\mathbf{p D}$ (Kolstad, Ulen, and Johnson 1990: 888; Burrows 1999: 227; Schmitz 2000: 371). There are, of course, advantages to private enforcement; in particular, as we have seen, the aggrieved individual consumer stands personally to benefit from a successful claim and thus has a motivation for an efficient investment in enforcement, balancing the costs of taking action against the private benefits, principally compensation, which should result (Landes and Posner 1975: 1). This does not apply to a public official; on the other hand, the private individual will not take into account the social benefits of enforcement, notably deterring losses to other consumers (Van den Bergh 2007: 187-89). Thus, while it is not difficult to justify the existence of the private right regime as complementing the public law regime, where there is likely to be repeated or widespread consumer losses, some degree of public enforcement is necessary.

Moreover, in practice, a private right might not be enforced for a variety of familiar reasons. The consumer might not know of the facts that constitute the infringement, or that a private legal remedy is available, the claim may be legally uncertain, or the trader may be insolvent or otherwise judgment proof. Most significantly, the costs of obtaining adequate evidence of the infringement and of instituting remedial proceedings may be too high, relative to any compensation to which the infringement may give rise.

Of course, there are many general ways of enhancing consumer awareness of rights and facilitating legal proceedings by consumers to overcome these difficulties. They include not only the provision of institutions, such as small claims courts, for the cheaper adjudication of disputes, but also, and more controversially, the enabling of "class" or "group" legal actions, and the granting of "punitive" or "triple" damages as compensation for the infringement of certain private rights. Consideration of these devices goes 
beyond the scope of the present article, although, as the literature indicates, the economic arguments for them are not always straightforward (Baldwin 1997; Boyd and Ingberman 1999: 47; Schaefer 2000: 183).

Less contentious, perhaps, are legal devices that, by linking private rights to public law enforcement, can be used to facilitate private law claims, at the same time enhancing compliance with the regulatory regime. There are three main possibilities. First, contravention of consumer protection regulatory regimes, leading to losses sustained by the consumer, might itself give rise to a right under private law for compensation, in other words tortious or delictual liability, obviating the need for the consumer to fulfill the normal conditions of liability (for example, the existence of a "duty of care" or the commission of a fault) (Faure and Van den Bergh 1987: 95; Ogus, 2006: 96-99). Second, the private claim might formally be joined to the public law enforcement process, as, for example, with the "partie civile" familiar in some European legal systems (Chiavario 2005: chap. 10), thus enabling the consumer to rely on the evidence furnished for the public law action (Hodges 2001: 321). Third, if the latter is not feasible, procedural law may enable the consumer to use an administrative or civil determination or a criminal conviction as evidence for the purpose of an independent private law action. ${ }^{30}$ The availability of these devices is much dependent on legal culture, particularly as regards civil procedure, but intuitively it may be surmised that any costs to which they may give rise are outweighed by the savings on information and administrative costs incurred by consumervictims and the increased deterrence to which they should give rise.

The extent to which consumer-victims, competitor traders, and other third parties are allowed to contribute to public law enforcement by, for example, initiating an administrative or criminal action against the trader, varies greatly across jurisdictions. ${ }^{31}$ At first glance, there would appear to be a strong cost-effective deterrence argument for allowing such participation: it should raise the values of $\boldsymbol{q}$ and $\boldsymbol{p}$, at no extra cost to taxpayers. And there are concomitant advantages: by providing, in effect, a competing enforcement agency, it can circumvent problems, including corruption, arising from the "private capture" of public institutions and their officials (Van den Bergh 2007: 201-02).

On the negative side, however, third-party activism can defeat, or at least undermine, sensible enforcement policy, where this dictates that a given trader should not be the subject of formal enforcement procedures. We have already seen ${ }^{32}$ that in some circumstances - notably in relation to first offenders committing minor contraventions - taking administrative, civil, or criminal proceedings may not be efficient. The motivation of the third party is likely to differ from that of deterrence. In the case of a consumer it may be to exact vengeance or at least to secure some compensation. In the case of another trader, it may simply be to impose costs on a competitor and thus seek to exclude the latter from the market (McAfee and Vakkur 2005: 37). These motivations, particularly as regards consumer compensation, are 
not always inappropriate, and it is a question of balancing their social value against the additional costs to which they give rise.

\section{CONCLUDING REMARKS}

Our article deals with a topical issue in many jurisdictions, how a high level of compliance with consumer protection legislation designed to prevent financial losses can be secured. The starting point for our analysis is the fact that across jurisdictions, there are apparently large differences in enforcement models. In broad terms, we distinguish between jurisdictions that rely respectively on administrative law, criminal law, or civil law as the main instrument for compliance, as well as systems where enforcement is mainly left either to consumers or consumer associations, or to an institution like an ombudsman, and where, therefore, administrative and/or criminal enforcement basically serves to back up the self-regulatory process.

Given these large differences, we use a theoretical framework based on economic analysis of law to address some of the key policy options. The economic framework (outlined in Section III) leads us to identify some key elements of an enforcement regime and to indicate in what circumstances one can expect a particular solution to be more or less cost effective.

We contend that a system of monitoring of trader's behavior by public authorities, sometimes supported by a system of risk assessment, is likely to be cost effective when there is not within the jurisdiction a significant culture of proactive complaints by consumers (or consumer associations) or where the contravention itself is unlikely to be easily detected by consumers themselves.

We then address the issue of postdetection enforcement discretion. In the specific case of a contravention of regulation protecting the consumer against financial losses, this usually relates to choosing between dismissing a case (with or without a warning) and initiating procedures for penalties. We argue that unless there are justified fears that officials might abuse discretion, it is cost effective to provide officials with such a postdetection discretion. Forcing agencies to prosecute in trivial cases may add disproportionately to the administrative costs of enforcement. Limiting action in relatively minor cases to, for example, a warning may enable the agency to maximize enforcement efforts within the available budget.

Some jurisdictions adopt a strategy of relying heavily on the activism of consumers themselves and/or representative consumer organizations, sometimes supported by self-regulation and alternative dispute resolution. The advantage of using these models where they exist is that it can substantially save on administrative costs of enforcement and, at the same time, exploit the incentive of the consumer victims to pursue their own case and thus enforce the legislation. Whether these self-regulatory mechanisms provide adequate deterrence depends largely upon the ability of the organization to 
impose sanctions and the possibility of applying pressure based on reputation of a trustmark to secure compliance from its members.

When a violation has been detected and enforcement is necessary, we argue that there are powerful cost-effectiveness arguments for allowing administrative agencies themselves to impose some form of financial penalty. The effectiveness of this sanction may, to a large extent, depend upon the judicial and administrative framework within the specific jurisdiction. A major advantage of the administrative financial penalty is that the costs of its imposition can be relatively low, certainly when compared to the criminal sanction. Thus, since also the probability of its imposition can be relatively high (given lower thresholds, e.g., of proof), the sanction itself need not be as large as in the criminal case to achieve effective deterrence. However, the flipside from the lower administrative costs resulting from a low-cost procedure is that error costs may be substantial. Therefore, we argue that so-called "naming and shaming" sanctions should not be used in this context given the danger of high error costs, unless the responsibility of the trader for the contravention has first been confirmed by a tribunal or court.

Civil financial penalties can, in theory, also be used even though not many jurisdictions seem to use them. When, however, a contravention is continuing, we argue that an injunction or enforcement order may be justified. This is more particularly the case when the contravention will lead to such a level of social harm that prevention of the continuing unlawful activity in the individual case is regarded as essential.

Given the high costs of criminal procedure, it should come as no surprise that from a cost-effectiveness perspective, we contend that criminal prosecutions should be reserved for repeat offenders who cannot be deterred by other instruments, as well as for those whose conduct is regarded as so repugnant morally as to justify such proceedings being taken, irrespective of deterrence considerations. The sanction to be imposed (in administrative, civil, or criminal proceeding) is preferably the financial penalty to be determined by reference to the nature of the contravention and the trader's circumstances (inter alia taking into account the profit gained as a result of the contravention). In many cases involving financial losses to consumers, a financial penalty may suffice to reach deterrence. However, where that penalty is insufficiently large for deterrence purposesfi (more particularly where the injurer's wealth may be limited and hence an insolvency problem arises) nonmonetary sanctions should be used to increase the likelihood of compliance. This could be compensation orders, orders for the recovery of administrative costs, the disgorgements of profits, or a policy of naming and shaming. Given the high costs, we argue that imprisonment should only be used as an ultimate sanction when deterrence cannot be reached through other means. However, other nonmonetary sanctions such as the suspension or revocation of a trading licence or a cease trading order (if applicable in the specific jurisdiction) may be more cost effective. 
Finally, we consider possibilities of using public law determinations that a trader has contravened consumer protection regulation to facilitate the enforcement of private rights by a victim who suffered a loss as a result of the violation. We also discuss the extent to which third parties should be able to initiate administrative or criminal actions against the trader. We consider that such action should be subject to approval by the relevant administrative agency primarily because the motivation of the third party (e.g., a competing trader) may diverge from the goal of cost-effective deterrence.

Our article merely discusses the enforcement of consumer legislation aiming at the prevention of financial losses. Similar questions concerning the relative effectiveness of the various enforcement mechanisms that we have discussed in this article also arise in other areas such as competition law. Although there are some features that are shared by consumer protection and competition law, there are also very important differences, not the least being the characteristics of law-breaking firms, of their victims, and of the losses that result.

The question also arises whether the indicators of cost-effective deterrence that we provide in this article are able also to explain some of the differences between the approaches that we found and described in Section II. To some extent, we assume this to be the case. Some legal systems may, for example, make use of a reactive approach to monitoring and may largely rely on selfregulatory mechanisms and consumer complaints simply because, in that particular jurisdiction, there is a culture of consumer activism. However we are, of course, aware of the fact that the differences between the jurisdictions may also reflect varying circumstances and, in particular, different legal traditions and cultures. If that is the case, it is highly unlikely that any single model of practices and procedures will provide the most cost effective means of achieving a high degree of compliance.

Our study should therefore be seen as an attempt not to identify a single optimal solution for the enforcement of relevant consumer regulation, but rather to provide an analytical framework for addressing the key policy options. We hope that by identifying the key variables that determine the cost effectiveness of various enforcement actions, we can help the policymaker to identify and understand the interaction of key variables that impact on the choice of enforcement practices and procedures. Moreover, it is important to reiterate that this article deals only with regulation protecting the consumer against potential financial losses. Regulation dealing with other kinds of losses (e.g., personal injury damage) would have different implications for the cost effectiveness of the various policy options.

MICHAEL FAURE is Academic Director of the METRO research institute and Professor of Comparative and International Environmental Law at the Maastricht University School of Law. He is also Professor of Comparative Private Law and Economics at the the Erasmus University of Rotterdam. 
ANTHONy Ogus is Erasmus Professor of Fundamentals of Private Law at the Erasmus University of Rotterdam and Emeritus Professor of Law at the University of Manchester. His research interests focus on law and economics and regulation.

NIELS PHILIPSEN is Assistant Professor of Law and Economics at the METRO research institute of Maastricht University School of Law. His research interests include the regulation of professions, competition law and policy, the economic analysis of accidents, and consumer policy.

\section{NOTES}

1. See OECD, "From Red Tape to Smart Tape: Administrative Simplification in OECD Countries" (2003); U.S. Office of Management and Budget, "Stimulating Smarter Regulation (Report to Congress, 2002); Canadian External Advisory Committee on Smarter Regulation, "Smarter Regulation: A Regulatory Strategy for Canada" (Report to the Government of Canada, 2004); UK Better Regulation Task Force, "Less is More" (2005); European Commission, "Strategic Review of Better Regulation in the European Union" $\{\mathrm{COM}(2006) 690$ final $\{$ COM(2006) 691 final .

2. The report was published as Best Practices for Consumer Policy: Report on the Effectiveness of Enforcement Regimes, DSTI/CP(2006)21/Final. Available at http://www.oecd.org/dataoecd/56/7/37863861.doc.

3. Regulatory Enforcement and Sanctions Bill, 2007.

4. For example, see Australia (Australian Law Reform Commission, Principled Regulation: Federal Civil and Administrative Penalties (2002) and Ministerial Council of Consumer Affairs, Civil Penalties for Australia's Consumer Protection Provisions, Discussion Paper September 2005 (2005)); Netherlands (Expertisecentrum rechtshandhaving, Monitoring beleidsinstrumentele wetgeving (1997) and Consumentenautoriteit, Consultatiedocument Oktober 2007 (2007)); and the United States (Simpson 2002); see, more generally, OECD, Reducing the Risk of Policy Failure: Challenges for Future Compliance (2000).

5. For a similar exercise in classification, see DTI (2003).

6. Regulatory Enforcement and Sanctions Bill, 2007.

7. This is an order to (1) establish a compliance program, (2) establish an education and training program, or (3) direct a person to revise the internal operations of his/her business; see Trade Practices Act §86C.

8. The author provides more information on the Scandinavian model.

9. $U$ may, of course, vary significantly across relevant traders. This, as we shall see in the later analysis, has important implications for targeting of the enforcement framework.

10. This is a simplified version of Becker's (1968) model. For more information on this model and the literature that followed it, see Eide (2000: 346-51) and Polinsky and Shavell (2000). See also Posner (1985) and Hylton (2005).

11. Indeed, with regard to criminal conviction, Funk (2004) argues that stigma is an important crime deterrent. Also Baldwin (2004) and Karpoff, Lott, and Wehrly (2005) provide empirical evidence suggesting that market reputation losses following criminal proceedings may have more impact on firms than the penalty itself.

12. However, these assumptions may be unrealistic for many individuals contemplating "mainstream" crimes, such as assault and theft.

13. Note again that, in our study, we considered areas of consumer protection regulation dealing only with financial losses; thus we exclude social cost which may arise from sickness and injury. 
14. Stigler deals with cost-benefit analysis and enforcement.

15. The extent to which account should also be taken of the costs imposed by the penalties and procedures on traders who have contravened the law is debatable. After all, these costs are the consequence of an illegal activity and the deterrence system depends on them facing such costs.

16. We mean before 2007 when a Consumer Authority was instituted.

17. These authors deal with the likelihood of collective private enforcement of consumer claims in general.

18. Officials recognized that this was indeed a weakness of the Dutch enforcement system.

19. According to Van den Bergh (2007), this is therefore the main argument in favor of public enforcement of this type of infringements of consumer laws.

20. For example, in Australia and Belgium, targeting takes place without relying on formal models.

21. See May and Winter (1999) for an example from the environmental area.

22. The costs of lost reputation to the industry, thus motivating effective self-regulation, may be enhanced by the threat of some residual intervention by a public regulator.

23. European Commission, The System of Administrative and Penal Sanctions in the Member States of the European Communities (1994, Office for Official Publications of the European Communities, Brussels).

24. See generally Garoupa and Gomez-Pomar (2004: 410), and, with respect to consumer legislation, Van den Bergh (2007: 198).

25. There is another reason for being concerned with high type I errors. If individuals, as a result of error, have a greater likelihood (or even certainty) of facing a fine, they may well choose the violation. Hence, type I errors can increase the set of individuals willing to breach the law.

26. On the dangers of over-deterrence, see Kobayashi (2001: 715).

27. There may be more differences between models (i) and (ii) if one were to incorporate potentially collusive behavior by agencies. Model (i) is potentially more prone to abusive rent extraction by the agency than model (ii). Hence, if the possibility of opportunistic behavior by bureaucrats is included, this may also affect the choice between models (i) and (ii).

28. The empirical work of Keith Hawkins $(1984,2005)$ underscores the importance of this point.

29. In this article we consider private rights as complementing a regulatory regime. We do not deal with the question whether, if only one type of regime is to be used, which of these is economically preferable. On this, see especially Shavell (1984: 357), Hylton (2002: 515), Faure (2007: 399-415), and Van den Bergh (2007: 186).

30. See, for example, for England and Wales, Civil Evidence Act 1968, §11.

31. See our OECD report: Report on the Effectiveness of Enforcement Regimes, DSTI/CP(2006)21/Final, Table 7. Available at http://www.oecd.org/dataoecd/56/ 7/37863861.doc.

32. See Section IV.

\section{REFERENCES}

Ammerlaan, Sjoerd, and Dirk Janssen (2007) "The Dutch Consumer Authority: An Introduction." In Collective Enforcement of Consumer Law. Securing Compliance in Europe through Private Group Action and Public Authority Intervention, edited by W. Van Boom \& M. Loos. Groningen: Europa Law Publishing.

Australia. Ministerial Council of Consumer Affairs (2005) Civil Penalties for Australia's Consumer Protection Provisions, Discussion Paper September 2005. Canberra: Ministerial Council on Consumer Affairs. 
Australian Law Reform Commission (2002) Principled Regulation: Federal Civil and Administrative Penalties. Available at http://www.austlii.edu.au/au/other/alrc/ publications/reports/95.

Ayres, Ian, and John Braithwaite (1992) Responsive Regulation: Transcending the Regulation Debate. New York: Oxford Univ. Press.

Baldwin, John (1997) Small Claims in the County Courts in England and Wales: The Bargain Basement of Civil Justice? Oxford: Oxford Univ. Press.

Baldwin, Robert (2004) "The New Punitive Regulation," Modern Law Review 67: 351-83.

Baldwin, Robert, and Julia Black (2008) "Really Responsive Regulation," Modern Law Review 71: 59-94.

Bardach, Eugene, and Robert A. Kagan (1982) Going by the Book: The Problem of Regulatory Unreasonableness. Philadelphia: Temple Univ. Press.

Bartle, Ian, and Peter Vass (2007) "Self Regulation within the Regulatory State: Towards a New Regulatory Paradigm," Public Administration 85: 885-905.

Becker, Gary S. (1968) "Crime and Punishment: An Economic Approach," Journal of Political Economy 76: 169-217.

Van den Bergh, Roger (2007) "Should Consumer Protection Law Be Publicly Enforced? An Economics Perspective on EC Regulation 2006/2004 and Its Implementation in the Consumer Protection Laws of the Member States." In Collective Enforcement of Consumer Law. Securing Compliance in Europe through Private Group Action and Public Authority Intervention, edited by W. Van Boom \& M. Loos. Groningen: Europa Law Publishing.

Van Boom, Willem, and Marco Loos (2007) "Effective Enforcement of Consumer Law in Europe; Private, Public and Collective Mechanisms." In Collective Enforcement of Consumer Law. Securing Compliance in Europe through Private Group Action and Public Authority Intervention, edited by W. Van Boom \& M. Loos. Groningen: Europa Law Publishing.

Bowles, Roger, Michael Faure, and Nuno Garoupa (2000) "Economic Analysis of the Removal of Illegal Gains," International Review of Law and Economics 20: 537-49.

Bowles, Roger, Michael Faure, and Nuno Garoupa (2005) "Forfeiture of Illegal Gain: An Economic Perspective," Oxford Journal of Legal Studies 25: 275-95.

Bowles, Roger, Michael Faure, and Nuno Garoupa (2008) "The Scope of Criminal Law and Criminal Sanctions: An Economic View and Policy Implications," Journal of Law and Society 35: 389-416.

Boyd, James, and Daniel E. Ingberman (1999) "Do Punitive Damages Promote Deterrence?" International Review of Law and Economics 19: 47-68.

Buell, Samuel W. (2006) "The Blaming Function of entity Criminal Liability," Indiana Law Journal 81: 473-537.

Burrows, Paul (1999) "Combining Regulation and Liability for the Control of External Costs,” International Review of Law and Economics 19: 227-44.

Calliess, Gralf-Peter (forthcoming) "Transnational Consumer Law: Co-Regulation of B2C-E-Commerce." In Responsible Business: Self-governance in Transnational Economic transactions, edited by O. Dilling, M. Herberg, \& G. Winter. Oxford: Hart Publishing.

Canadian External Advisory Committee on Smarter Regulation (2004) Smarter Regulation: A Regulatory Strategy for Canada (Report to the Government of Canada). Ottawa: External Advisory Committee on Smart Regulation.

Chiavario, Mario (2005) "Private Parties: The Rights of the Defendant and the Victim." In European Criminal Procedures, edited by M. Delmas-Marty et al. New York: Cambridge Univ. Press.

Eide, Erling (2000) "Economics of Criminal Behaviour." In Encyclopedia of Law and Economics, edited by G. De Geest \& B. Boeckaert. Cheltenham: Edward Elgar Publishing. 
European Commission (1994) The System of Administrative and Penal Sanctions in the Member States of the European Communities. Office for Official Publications of the European Communities. Brussels: National Reports.

European Commission (2006) Strategic Review of Better Regulation in the European Union. COM(2006) 690 final. Available at http://ec.europa.eu/enterprise/regulation/ better_regulation/docs/docs_admin_b/en_689.pdf.

Faure, Michael (2007) "Economic Analysis of Tort and Regulatory Law." In Tort and Regulatory Law, edited by W. H. Van Boom, M. Lukas, \& C. Kissling. Vienna: Springer.

Faure, Michael, Anthony Ogus, and Niels Philipsen (2008) "Enforcement Practices for Breaches of Consumer Protection Legislation," Loyola Consumer Law Review 20: 361-401.

Faure, Michael, and Roger Van den Bergh (1987) "Negligence, Strict Liability and Regulation of Safety under Belgian Law: An Introductory Economic Analysis," Geneva Papers on Risk and Insurance 12: 95-114.

Fenn, P., and C. G. Veljanovski (1988) "A Positive Economic Theory of Regulatory Enforcement," Economic Journal 98: 1055-70.

Funk, Patricia (2004) "On the Effective Use of Stigma as a Crime-Deterrent," European Economic Review 48: 715-28.

Garoupa, Nuno, and Fernando Gomez-Pomar (2004) "Punish Once or Punish Twice: A Theory of the Use of Criminal Sanctions in Addition to Regulatory Penalties," American Law and Economics Review 6: 410-33.

De Geest, Gerrit (2002) "The Signing-Without_-Reading Problem: An Analysis of the Directive on Unfair Contract Terms." In Konsequenzen wirtschaftlicher Normen, edited by H.-B. Schäfer \& H.-J. Lwowski. Wiesbaden: Gabler Verlag.

Gibbons, Thomas (1982) "The Utility of Economic Analysis of Crime," International Review of Law and Economics 2: 173-91.

Grabosky, Peter, and John Braithwaite (1986) Of Manners Gentle: Enforcement Strategies of Australian Business Regulatory Agencies. Melbourne: Oxford Univ. Press.

Great Britain. Department of Trade and Industry (DTI) (2003) Comparative Report on Consumer Policy Regimes. London: DTI.

Great Britain. Department of Trade and Industry (DTI) (2003) Enforcement Concordat: Good Practice Guide for England and Wales. London: DTI.

Great Britain. Better Regulation Task Force (2005) Regulation: Less Is More: Reducing Burdens, Improving Outcomes. London: Better Regulation Taskforce.

Gupta, Anil K., and Lawrence J. Lad (1983) "Industry Self-Regulation: An Economic, Organizational and Political Analysis," Academy of Management Review 8: 416-25.

Hadfield, Gillian K. (2001) "Privatizing Commercial Law," Regulation 24: 40-45.

Hawkins, Keith (1984) Environment and Enforcement, Regulation and the Social Definition of Pollution. Oxford: Clarendon Press.

Hawkins, Keith (2005) Law as a Last Resort. Oxford: Oxford Univ. Press.

Heyes, Anthony, and Neil Rickman (1999) "Regulatory Dealing-Revisiting the Harrington Paradox," Journal of Public Economics 72: 361-78.

Hodges, Christopher (2001) "Multi-Party Actions: A European Approach," Duke Journal of Comparative and International Law 11: 321-54.

Howells, Geraint (2007) "Enforcing Consumer Interests by Regulatory AgenciesThe British Experience. A Case Study of the Office of Fair Trading." In Collective Enforcement of Consumer Law. Securing Compliance in Europe through Private Group Action and Public Authority Intervention, edited by W. Van Boom \& M. Loos. Groningen: Europa Law Publishing.

Hutter, Bridget M. (1997) Compliance: Regulation and Environment. Oxford: Clarendon Press. 
Hylton, Keith N. (2005) "The Theory of Penalties and the Economics of Criminal Law," International Review of Law and Economics 1: 175-201.

Landes, William, and Richard A. Posner (1975) "The Private Enforcement of Law," Journal of Legal Sudies 4: 1-46.

Karpoff, Jonathan M., John R. Lott, and Eric W. Wehrly (2005) "The Reputational Penalties for Environmental Violations: Empirical Evidence," Journal of Law and Economics 48: 653-76.

Kobayashi, Bruce H. (2001) "Antitrust, Agency and Amnesty: An Economic Analysis of the Criminal Enforcement of the Antitrust Laws against Corporations," George Washington Law Review 69: 715-44.

Kolstad, Charles D., Thomas S. Ulen, and Gary V. Johnson (1990) "Ex Post Liability for Harm vs. Ex Ante Safety Regulation: Substitutes or Complements?" American Economic Review 80: 888-901.

Lubbers, Jeffrey S., Rex Deighton-Smith, Peter Ladegaard, Cesar Cordova-Novion, Peter Czaga, and Rolf G. Alter (2003) From Red Tape to Smart Tape: Administrative Simplification in OECD Countries. Paris: OECD.

Macrory, Richard B. (2006) Regulatory Justice: Making Sanctions Effective. Final report. London: Cabinet Office. Better Regulation Executive.

May, Peter J., and Søren Winter (1999) "Regulatory Enforcement and Compliance: Examining the Danish Agro-Environmental Policy," Journal of Policy Analysis and Management 18: 625-51.

McAfee, R. Preston, and Nicholas V. Vakkur (2005) "The Strategic Abuse of the Antitrust Laws," Journal of Strategic Management Education 1: 37-55.

Micklitz, Hans-W. (2007) "Collective private Enforcement of Consumer Law: The Key Questions." In Collective Enforcement of Consumer Law. Securing Compliance in Europe through Private Group Action and Public Authority Intervention, edited by W. Van Boom \& M. Loos. Groningen: Europa Law Publishing.

Morris, Norval, and Michael Tonry (1990) Between Prison and Probation: Intermediate Punishment in a Rational Sentencing System. New York: Oxford Univ. Press.

The Netherlands. Expertisecentrum rechtshandhaving (1997) Monitoring beleidsinstrumentele wetgeving. Den Haag: Ministerie van Justitie, Inspectie voor de Rechtshandhaving.

The Netherlands. Consumentenautoriteit (October 2007) Consultatiedocument. Available at http://www.consumentenautoriteit.nl/dsresource?objectid=11963\&type=pdf.

Ogus, Anthony (1995) "Rethinking Self-Regulation," Oxford Journal of Legal Studies 15: 97-108.

Ogus, Anthony (2004) Regulation: Legal Form and Economic Theory. Portland, OR: Hart Publishing.

Ogus, Anthony (2006) Costs and Cautionary Tales: Economic Insights for the Law. Oxford: Hart Publishing.

Ogus, Anthony (2007) "Better Regulation-Better Enforcement." In Better Regulation, edited by S. Weatherill. Oxford: Hart Publishing.

Ogus, Anthony, and Carolyn Abbot (2002) "Sanctions for Pollution: Do We have the Right Regime?," Journal of Environmental Law 13: 283-98.

Ogus, Anthony, Michael Faure, and Niels Philipsen (2006) Report on the Effectiveness of Enforcement Regimes. Paris: OECD.

Parker, Christine (2000) Reducing the Risk of Policy Failure: Challenges for Regulatory Compliance. Paris: OECD.

Polinsky, A. Mitchell, and Steven Shavell (2000) "The Economic Theory of Public Enforcement of Law," Journal of Economic Literature 38: 45-76.

Posner, Richard A. (1985) "An Economic Theory of the Criminal Law," Columbia Law Review 85: 1193-231.

Posner, Richard A., and Eric B. Rasmusen (1999) "Creating and Enforcing Norms with Special Reference to Sanctions," International Review of Law and Economics 19: 369-82. 
Posner, Richard A., and Eric B. Rasmusen (2003) "Shame, Stigma and Crime: Evaluating the Efficacy of Shaming Sanctions in Criminal Law," Harvard Law Review 116: 2186-207.

Rasmusen, Eric (1996) "Stigma and Self-Fulfilling Expectations of Criminality," Journal of Law and Economics 39: 519-43.

Richardson, Genevra, et al. (1984) Policing Pollution: A Study of Regulation and Enforcement. Oxford: Clarendon Press.

Schäfer, Hans-Bernd (2000) "The Bundling of Similar Interests on Litigation. The Incentives for Class Actions and Legal Actions taken by Associations," European Journal of Law and Economics 9: 183-213.

Schmitz, P. W. (2000) "On the Joint Use of Liability and Safety Regulation," International Review of Law and Economics 20: 371-82.

Simpson, Sally S. (2002) Corporate Crime, Law and Social Control. New York: Cambridge Univ. Press.

Stigler, George J. (1970) "The Optimum Enforcement of Laws," Journal of Political Economy 78: 526-36.

U.S. Office of Management and Budget (2002) Stimulating Smarter Regulation (Report to Congress). Available at http://www.whitehouse.gov/omb/inforeg/ 2002_report_to_congress.pdf.

Viitanen, Klaus (2007) "Enforcement of Consumers' Collective Interests by Regulatory Agencies in the Nordic Countries." In Collective Enforcement of Consumer Law. Securing Compliance in Europe through Private Group Action and Public Authority Intervention, edited by W. Van Boom \& M. Loos. Groningen: Europa Law Publishing. Vogel, David (1986) National Styles of Regulation: Environmental Policy in Great Britain and the United States. Ithaca, NY: Cornell Univ. Press.

Wotruba, Thomas R. (1997) "Industry Self-Regulation: A Review and Extension to a Global Setting," Journal of Public Policy and Marketing 16: 38-54.

Yeung, Karen (2004) Securing Compliance: A Principled Approach. Oxford: Hart Publishing.

\section{LEGISLATION CITED}

England and Wales

Civil Evidence Act , §11 (1968).

Great Britain

Regulatory Enforcement and Sanctions Bill (2007). 